\title{
Influence of Intravesical Lower pH on the Micturition Reflex Threshold in the Rat
}

\author{
Peng Zeng1, Shaohua Zeng1, Chonghe Jiang1,2*, Janwen Zeng1, Jianfeng Mo1, \\ Sivert Lindström² \\ ${ }^{1}$ Department of Urology, Qingyan City People's Hospital of Jinan University, Guangdong, China \\ ${ }^{2}$ Department of Clinical and Experimental Medicine, University of Linköping, Linköping, Sweden \\ Email: ${ }^{*}$ chonghe.jiang@gmail.com
}

Received 10 October 2014; revised 20 November 2014; accepted 1 December 2014

Copyright (C) 2014 by authors and Scientific Research Publishing Inc.

This work is licensed under the Creative Commons Attribution International License (CC BY).

http://creativecommons.org/licenses/by/4.0/

(c) (i) Open Access

\begin{abstract}
Aims: To investigate whether intravesical lower $\mathrm{pH}$ induces a micturition threshold reflex change of anaesthetized rats. Methods: Thirteen female rats, anaesthetized by $\alpha$-chloralose and paralyzed by pancurone bromide were used for the experiments. The micturition threshold volume was determined by repeated cystometry. Simultaneously bladder afferent activities in four and efferent activities in seven rats were recorded from the exposed pelvic nerve to the bladder. Results: Cystometry with acidic saline at $\mathrm{pH} 3$ and 4 induced a significant decrease in micturition threshold volume. The mean value of these groups of test showed that bladder compliance, micturition threshold pressure and maximal micturition contraction pressure were decreased significantly comparing with the controls. There were no changes in all other parameters recorded from afferent and efferent, e.g. afferent threshold volume, afferent or efferent activity at the micturition threshold and their peak activity at the micturition contraction. Conclusions: Acidic solution provoked sensitivity but reduced the force of the contractility to the urinary bladder. The effect was presented without a detectable change in the firing properties of bladder A $\delta$ mechanoreceptor afferents. It is proposed that proton sensitive bladder receptors with unmyelinated afferent were stimulated by the acidic solution and that the micturition reflex was facilitated by afferent inflow from such receptors. The findings were clinically important in choosing the medium for urodynamic examination.
\end{abstract}

\section{Keywords}

pH, Urinary Bladder, Micturition Threshold Volume, Afferent, Efferent, Rat

${ }^{*}$ Corresponding author.

How to cite this paper: Zeng, P., Zeng, S.H., Jiang, C.H., Zeng, J.W., Mo, J.F. and Lindström, S. (2014) Influence of Intravesical Lower pH on the Micturition Reflex Threshold in the Rat. Open Journal of Urology, 4, 143-150.

http://dx.doi.org/10.4236/oju.2014.412025 


\section{Introduction}

The normal micturition reflex is triggered by activation of bladder mechanoreceptor A $\delta$ afferents when certain amount of bladder volume reached or voluntary commanded. Besides, other reflexes, which are involved in pathological situation of urinary bladder, have also been reported. For instance, bladder-to-bladder cooling reflex was identified by the injection of cold solution to the bladder [1]. The reflexes are initiated by bladder cooling receptor C-afferent. Bladder urgency or instability can be provoked by the solutions with high osmolarity or potassium in the bladder, although their working mechanisms are not well-clarified [2]-[4].

In human, the desire to void is influenced by urinary $\mathrm{pH}$ - the desire is being experienced at lower bladder volumes when the urine is more acidic [5]. Detrusor contractions can also be provoked in many patients by instillation of acidic solutions into the bladder [6]. Although the defect of blood-urine barrier was supposed to be the reason under the observations, the neurogenical mechanisms have not been formally investigated [2] [4] [7]. The aim of the present experimental study in the rat was to modulate the micturition threshold by infusion of fluid at different $\mathrm{pH}$ and to identify associated changes in bladder afferent and efferent activities.

\section{Material and Methods}

Thirteen female rats (Sprague-Dawley, 300 - 350 g) were included in this study. Methohexitone (Brietal, Lilly, $30 \mathrm{mg} / \mathrm{kg}$ i.p.) was used for initial anaesthesia during surgical preparation. Animals were then transferred to $\alpha$ chloralose (initial dose $70 \mathrm{mg} / \mathrm{kg}$ i.v., followed by a continuous i.v. infusion of 10 - $15 \mathrm{mg} / \mathrm{kg} . \mathrm{h}$ ) to maintain an appropriate, stable depth of anaesthesia for the entire recording period. To maximize stability, they were also paralyzed by pancuronium bromide (Pavulon, Organon, $0.6 \mathrm{mg} / \mathrm{kg}$ i.v., supplemented by $0.3 \mathrm{mg} / \mathrm{kg} / \mathrm{hr}$ ) and artificially ventilated with end-expiratory $\mathrm{CO}_{2}$ adjusted to about $3.5 \%$. The infusion rate of $\alpha$-chloralose had previously been determined to be adequate, when tested on unparalyzed animals [8]. In addition, lack of heart rate changes in response to strong pinches of the paw was used to verify that animals remained sufficiently anesthetized throughout the experiment. External jugular vein and carotid artery were cannulated to allow fluid injections and blood pressure recordings. The central body temperature was kept at $38^{\circ} \mathrm{C}$ by a feed-back controlled heating lamp. The experiments were approved by The Animal Research Ethical Committee of Linköping in accordance with Swedish law.

For cystometry, a polyethylene catheter (PE 90) was inserted into the bladder through a slit in the proximal urethra and connected in parallel to an infusion pump and a pressure transducer. For bladder neurogram, a thin nerve branch to the bladder was dissected distal to the major pelvic ganglion. The nerve branch was transected close to the ganglion for afferent recordings ( 6 rats) and close to the bladder wall for efferent recordings (7 rats, Figure 1). Multi-unit afferent and efferent activity was recorded by hooking the nerve branches onto a bipolar platinum wire electrode (inter-electrode distance 1 - $2 \mathrm{~mm}$ ). Due to the anatomical arrangements in rats [9], the efferent recordings were from post-ganglionic fibers. The afferent activity originated primarily from myelinated A $\delta$ afferents which have considerably larger spike amplitudes than C-afferents in this kind of recordings. The exposed bladder and nerves were covered by body warm paraffin oil in a pool formed by sewn up skin flaps. The bladder was handled carefully throughout the experiment to avoid unintentional sensitization of its sensory receptors.

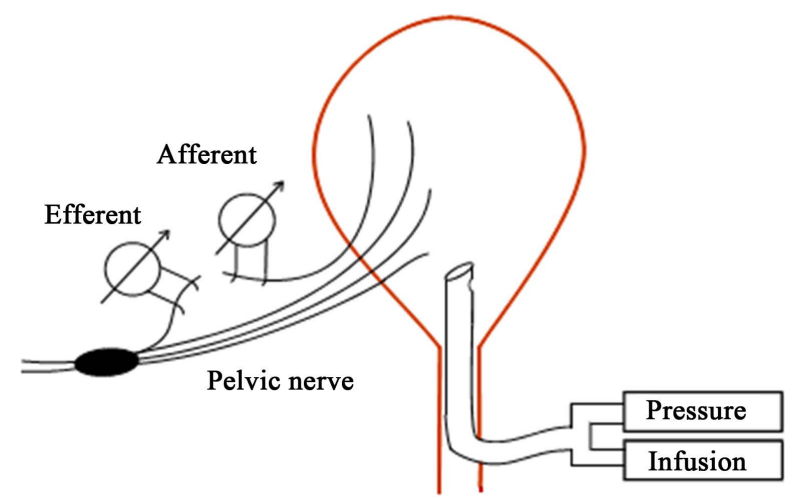

Figure 1. Diagram of experimental arrangements. 
Micturition threshold volume was used as dependent variable, determined by repeated cystometries. Infusion speed $(0.2-0.06 \mathrm{ml} / \mathrm{min})$ was adjusted by the bladder size, which determined by fill the bladder to micturition threshold in about 3 minutes. As soon as a micturition contraction occurred, infusion was interrupted by opening the bladder catheter. Care was taken to empty the bladder completely after each cystometry by lowering the catheter outlet below the bladder. The resting period, with the bladder empty and open, was usually more than 3 minutes before the start of the next cystometry.

After an initial equilibrium period, four control cystometries were performed with body-warm saline at $\mathrm{pH} 7$. Then different acidic solutions ( $\mathrm{pH} \mathrm{3,} \mathrm{4,} \mathrm{5,} \mathrm{and} \mathrm{6)} \mathrm{were} \mathrm{tested} \mathrm{in} \mathrm{irregular} \mathrm{order.} \mathrm{Each} \mathrm{test} \mathrm{trial} \mathrm{consisted} \mathrm{of} 4$ consecutive cystometries with the same acid solution at body temperature, followed by another 4 control cystometries with saline. Due to residual solution in the infusion system (dead space about $0.05 \mathrm{ml}$ ), the first infusate in a sequence of four was contaminated by the previously used solution and of intermediate $\mathrm{pH}$. Contamination was negligible for following cystometries. Therefore, the first cystometry after a solution change was omitted and all measurements based on the following three in a trial sequence. For analysis, the mean micturition threshold volume of the three trial cystometries was compared with the mean of the three immediately preceding control cystometries. Since control threshold volume varied between animals by more than a factor of 2 , these values were normalized and expressed as a percentage of the control value.

Bladder pressure, afferent or efferent nerve activity together with the full-wave rectified and integrated nerve responses were continuously recorded on a digital HIOKI chart recorder and subsequently analyzed off-line with a PC based system [10]. The following parameters were studied: afferent and efferent threshold volumes, micturition threshold volume and pressure, afferent activity at micturition threshold, peak afferent and efferent activity, bladder pressure at peak Edible mushrooms of the dense forests of Central Africa Taxonomy and Identification activity (using iso-volumetric recordings). In each trial, the mean values of these parameters were determined from three consecutive cystometries as above.

Student's paired t-test (two-tailed) was used for statistical analysis of normalized, otherwise the Wilcoxon signed rank test. Significant differences were defined as $P<0.05$.

\section{Results}

A total 534 cystometries were performed in 13 rats. After elimination of transition cytometries (Methods), the micturition threshold volume could be determined in 389 cystometries, corresponding to 27, 14, 13, 14 and 68 exposure trials at $\mathrm{pH} 3,4,5,6$ and 7 respectively. The mean threshold volume was decreased for each $\mathrm{pH}$ group although the effect was only significant for $\mathrm{pH} 4$ (from 0.51 to $0.47 \mathrm{ml} ; P<0.01$ ) and $\mathrm{pH} 3$ (from 0.52 to $0.42, P$ $<0.001$ ). To minimize variability between animals, the threshold values were normalized and expressed as a percentage of the control values for each trial. With this procedure the threshold volume was decreased to $81 \%$ of controls for $\mathrm{pH} 3$ and to $93 \%$ for $\mathrm{pH} 4$ solutions (Figure 2).

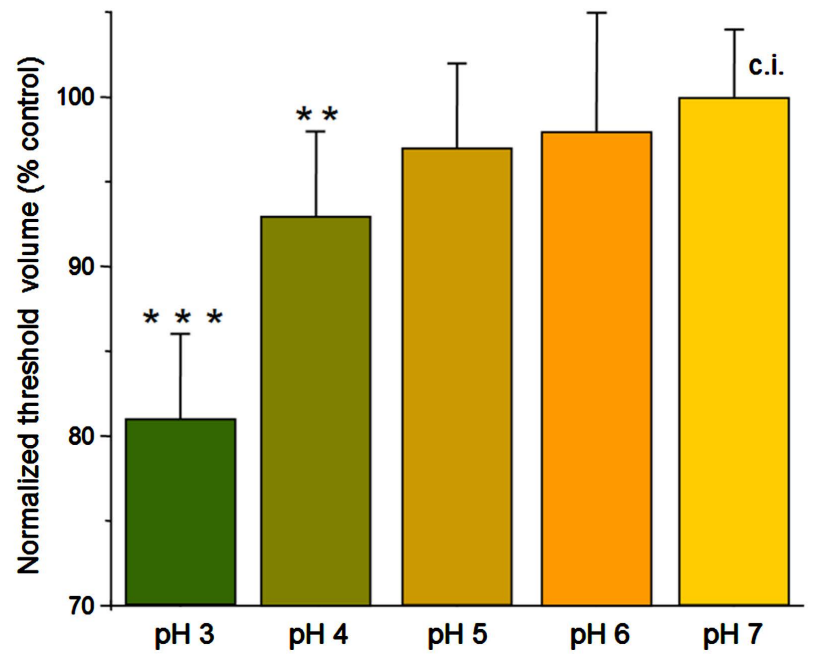

Figure 2. Normalized micturition threshold volumes for cystometries with

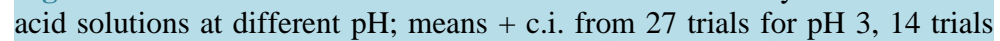
for $\mathrm{pH} 4,13$ trials for $\mathrm{pH} 5,14$ trials for $\mathrm{pH} 6 .{ }^{* * *} P<0.001,{ }^{*} \mathrm{P}<0.05$. 
Our brief exposures of the bladder to acidic solutions resulted in a changed micturition threshold volume that was fully reversible. Thus, the threshold volume typically returned to control values on re-exposure to saline. These consistent changes are illustrated in Figure 3 with values from 4 animals exposed to a solution at $\mathrm{pH} 3$. The fact that the $\mathrm{pH}$ effect was fully reversible was a prerequisite for the possibility to run several low $\mathrm{pH}$ trial in sequence in the same animal (mean 5.2 trials/rat; range 2 - 8). Thus, early exposure of the bladder to $\mathrm{pH} 3$ fluids did not affect subsequent trials with less acidic solutions. It is further noteworthy that detrusor instability did not develop with our procedure, not even at infusion of our strongest acid solution ( $\mathrm{pH} \mathrm{3}$; see Figure 4 and Figure 5). This result is in contrast to previous publications where acid exposure was used as an animal model for interstitial cystitis (IC) [11] [12].

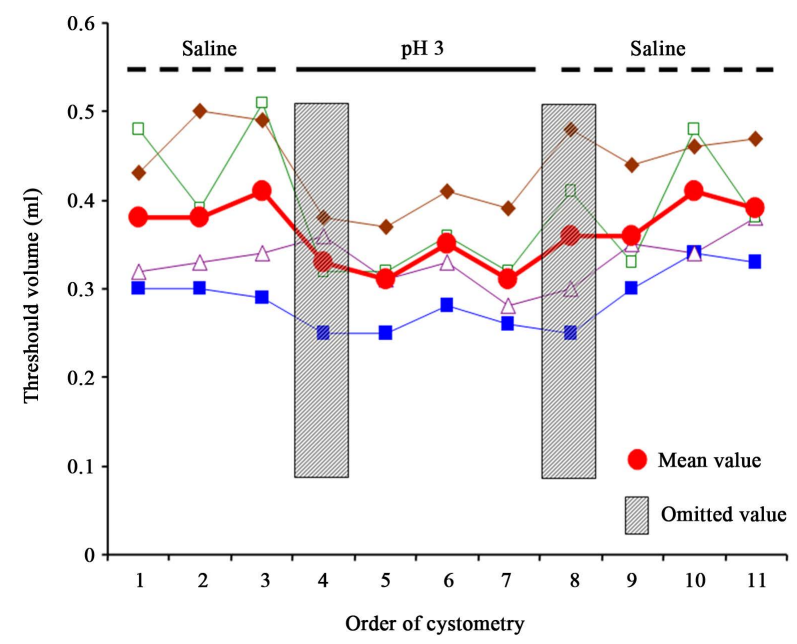

Figure 3. Change in micturition threshold volume during a sequence of cystometries with control fluid at $\mathrm{pH} 7$ and acid fluid at $\mathrm{pH} 3$ in 4 different animals. Large round symbols indicate mean values of this representative sample. First transition cystometries, marked by dashed bars, were omitted from the analysis, see Methods. Note full recovery of threshold values after the return to control fluid. The illustrated sequence required an experimental time of about 1.5 hour.
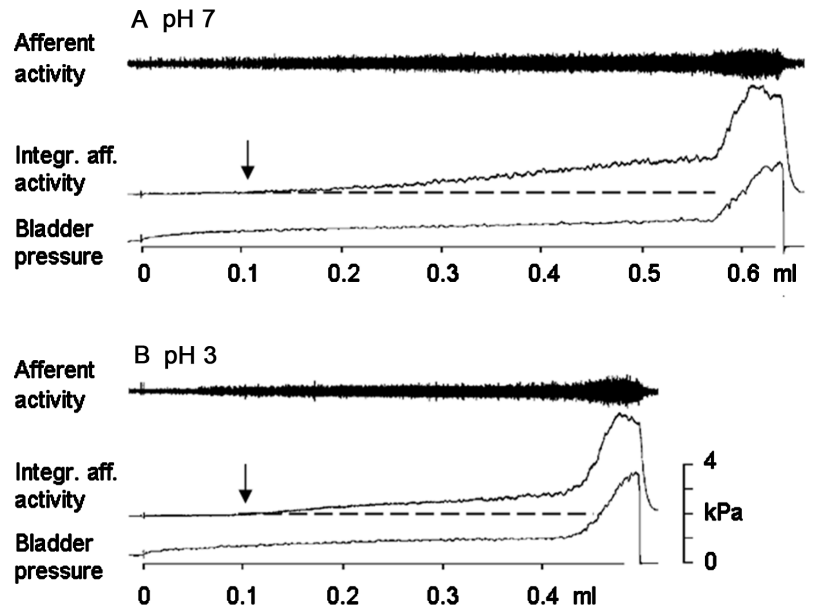

Figure 4. Afferent activity during cystometry with control fluid at $\mathrm{pH} 7$ (A) and acid fluid at $\mathrm{pH} 3$ (B). Upper trace is a multiunit recording from the distal end of a bladder nerve filament transected close to the pelvic ganglion, middle trace the corresponding integrated activity, lower trace the bladder pressure under iso-volumetric condition. Arrows at integrated responses in A and B mark the afferent threshold volume. Note lack of change in afferent activity despite a marked reduction in micturition threshold volume by the $\mathrm{pH} 3$ infusate in $\mathrm{B}$. Infusion speed $0.2 \mathrm{ml} / \mathrm{min}$. 


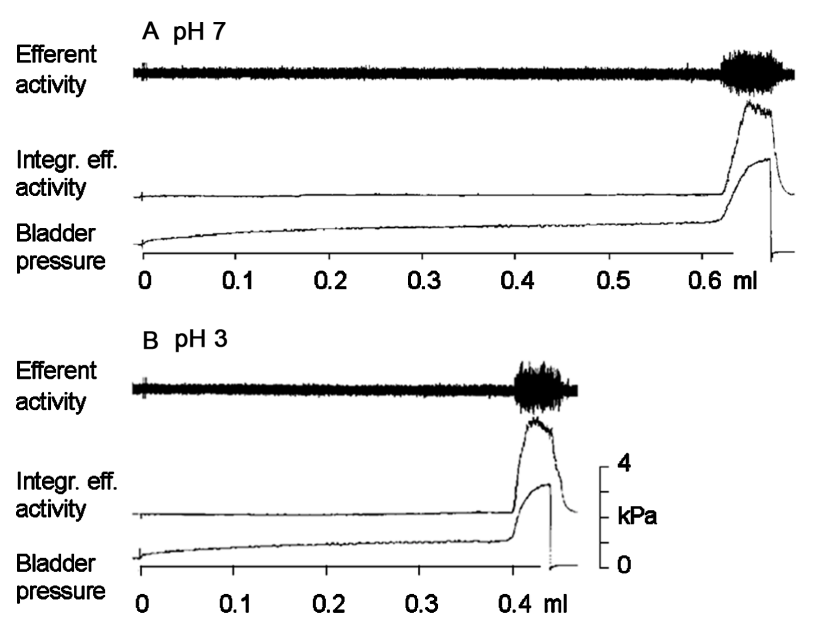

Figure 5. Efferent activity during cystometry with infusate at $\mathrm{pH} 7$ (A) and $\mathrm{pH} 3$ (B). Multiunit recordings from the proximal end of a bladder nerve filament transected close to the bladder, other details as in Figure 4. Note lack of efferent activity during the bladder filling phase both in A and B.

The bladder pressure at micturition threshold was somewhat decreased by low $\mathrm{pH}$ fluids (as would be expected by the decrease in threshold volume). Pooling data from trials with $\mathrm{pH} 3$ and $\mathrm{pH} 4$ exposures (34 trials), the mean micturition threshold pressure decreased from 1.05 to $0.98 \mathrm{kPa}(P<0.05)$. The bladder compliance was also decreased following acid exposure (from 5.3 to $4.8 \mathrm{ml} / \mathrm{kPa} ; P=0.001$ ). This small change in bladder stiffness was entirely due to trials with fluid at pH 3 (18 trials), while there was no discernable change in compliance following cystometries with $\mathrm{pH} 4$ solution (16 trials; $P=0.90$ ). There was also a marginal but significant decrease in maximal bladder pressure at peak activity following acid exposure (from 4.07 to $3.88 \mathrm{kPa} ; P<0.05$ ). This small change is presumably explained by the decrease in bladder volume and the typical pressure/volume curve for rats [13] [14].

\subsection{Effect of Lower pH on Bladder Afferent Activity}

The effect of acid (pH 3 and 4) on bladder afferent activity was studied with multiunit recordings in 12 trials (6 at $\mathrm{pH} 3,5$ at $\mathrm{pH} 4$ ) in 4 rats. This type of recording is dominated by the activity in large afferents from low threshold bladder mechanoreceptors. During a typical cystometry, the afferent activity increases very gradually up to the onset of the micturition contraction (Figure 4). At this point, the rise in bladder pressure causes a very pronounced afferent activation. This pattern of activity is best appreciated from the integrated response providing a quantitative representation (middle trace, Figure 4). The point where the integrated response started to deviate from baseline (arrow, middle trace) was used to define the afferent threshold volume. In the illustrated case, the micturition threshold volume decreased from $0.58 \mathrm{ml}$ to $0.43 \mathrm{ml}$ when infusions were changed from saline to a fluid at pH 3 (Figure 4(B)). However, the afferent threshold volume, afferent activity at micturition threshold and peak afferent activity remained unchanged.

Likewise, there was no significant change in any of these afferent parameters when data from all 12 trials were pooled. The mean afferent threshold volume was $0.12 \mathrm{ml}$ with saline and $0.11 \mathrm{ml}$ with acid solution $(P=$ 0.17), the mean afferent peak activity 35.0 and $35.7(P=0.38)$ and mean afferent activity at micturition threshold 10.3 and $9.5(P=0.19)$ in relative values from the integrated response. Clearly, the mechanoreceptor response was not affected at these $\mathrm{pH}$ levels.

\subsection{Effect of Low pH on Efferent Activity}

Postganglionic efferent activity was recorded in 22 exposure trials at $\mathrm{pH} 3$ and $\mathrm{pH} 4$ in 7 rats. Typically, there was no detectable efferent activity during the bladder filling phase until just before onset of the micturition contraction, neither in control nor in low $\mathrm{pH}$ cystometries (Figure 5). Accordingly, the efferent threshold volume decreased in parallel with the micturition threshold volume from 0.57 to $0.48 \mathrm{ml}(P<0.001)$ in this subgroup of trials. The peak efferent activity remained unchanged (33.2 versus 32.5 in relative values; $P=0.62$ ). 


\section{Discussion}

This animal experiment study demonstrated that cystometry with acidic solutions induced a significant decrease in the micturition volume. The rat was anaethtized by the continues i.v. infusion of $\alpha$-chloralose and paralyzed by pancurone bromide. The infusion speed of drug was adjusted to keep the bladder stable during the data acquisition. Under this circumstance, repeated cystometries with saline $(\mathrm{pH} 7)$ in an interval of 3 - 5 minutes showed no significant differences for the micturition contraction threshold volume in the pilot studies and our previous reports [10]. Hence, the volume threshold changes by low $\mathrm{pH}$ solutions could not explain by the influences of anaethetisa. It was due to the bladder chemical receptors activated by the acidic solutions and in consequence the facilitation of the micturition reflexes. Downgrade $\mathrm{pH}$ test showed that the effect was concentration dependent of acidity. A significant decrease effect on the micturition threshold volume required the solution had the $\mathrm{pH}$ lower than 4, although $\mathrm{pH} 5$ and 6 showed some influences. Normally, urine $\mathrm{pH}$ is four times lower than blood $\mathrm{pH}$ and $\mathrm{pH} 4$ - 5 is within physiological solution in the bladder. Previous experiment in rat established that both afferent and efferent recordings were normal bladder mechanoreceptors A $\delta$ fibers activities. There were no changes in afferent and efferent activities, although the bladder excitability was increased after acidic stimulation to the bladder. Obviously, such a lower $\mathrm{pH}$ solutions $(3-4)$ were a noxious stimulation to the chemical receptors $\mathrm{C}$ fiber afferents in the bladder wall. Studies both clinically in patient and experimentally in rat showed that high $\mathrm{pH}$ urine induced increasing and lower $\mathrm{pH}$ urine caused decreasing in bladder capacity [7] [15]. The same result was demonstrated in our acute $\alpha$-chloralose anaesthetized rat. It was reasonable to proposed that the decrease in micturition threshold volume was due to the decrease in bladder capacity after the acidity stimulation. Acidic solution enhanced the bladder sensation and in consequence facilitated the micturition reflex so the micturition contraction started at the lower threshold volume.

Significant decreases in micturition threshold pressure and maximal micturition contraction pressure indicate that the bladder contractility became weaker by the lower $\mathrm{pH}$ stimulation. The results were in keeping with the report that lower $\mathrm{pH}$ urine was an irritated stimulation in causing the bladder instability. It manifested as the micturition reflex was more frequent with lower threshold volume and weaker detrusor contractility [15]-[17]. Lower $\mathrm{pH}$ solutions with high proton promoted bladder nerve depolarization so the detrusor excitability was enhanced. The prerequisite for the easier depolarization is that the blood-urine barrier was insufficient and the filtration of proton ion is higher to the sub-mucous and musculature nerve fibers. In a small separate group of experiment we tried different infusion speed and showed that the higher speed $(0.35 \mathrm{ml} / \mathrm{min})$ had more effect on the decrease in threshold volume than our standard infusion speed. Slower speed $(0.1 \mathrm{ml} / \mathrm{min})$ had less effect. We think that the more effect with higher infusion speed was not only due to the quick strong stimulation but also involved the higher penetration of urothelium of the bladder [4] [7].

The findings that both the decrease in micturition threshold volume and the weaker detrusor contractility induced by the acidity intravesical stimulation were not involved in the bladder $A \delta$ mechanoreceptor afferents. Firstly, the weaker acidification stimulation did not affect very much. Only the $\mathrm{pH}$ lower than 4 could induce the effect, which is nociceptive stimulation [18] [19]. The afferent and efferent activity did not change the results between control and acid cytometries. It indicates that the micturition reflex pathway was not influenced by the acidity stimulation, although bladder capacity and bladder contractility were decreased. The decrease occurred without a detectable change in the firing properties of bladder A $\delta$ mechanoreceptor afferents. We proposed that proton sensitive bladder receptors with unmyelinated afferents were stimulated by the acidic solution and that the micturition reflex was facilitated by afferent inflow from such receptors [20] [21]. Furthermore, the data shows that the bladder compliance was also significant decrease with the acidic cystometries, which indicates that the bladder stiffness was increase. The stiffness change by acid was either due to weakness of the detrusor fibers or the decrease in detrusor of the muscle elasticity. It was proposed that non-obstructive frequency was due to an adaptive mechanism of the body to protect the kidneys from recirculated load [22]. The decrease in bladder compliance in this study is in agreement with this proposing that leads to the urinary frequency. The finding was clinically important in choosing the solution for urodynamic examination.

\section{Conclusion}

Acidic solution provoked sensitivity but reduced the force of the contractility to the urinary bladder. The effect was presented without a detectable change in the firing properties of bladder A $\delta$ mechanoreceptor afferent. It is proposed that proton sensitive bladder receptors with unmyelinated afferent were stimulated by the acidic solu- 
tion and that the micturition reflex was facilitated by afferent inflow from such receptors. The findings were clinically important in choosing the medium for urodynamic examination.

\section{Disclosures}

No conflicts of interest are declared by the authors.

\section{Acknowledgements}

This study was supported by the Swedish Medical Research Council (projects no 04767), the County of Östergötland, Sweden (LIO-4904) and Qingyuan City People’s Hospital of Jinan University, China.

\section{References}

[1] Fall, M. and Lindstrom, S. (1991) Electrical Stimulation. A Physiologic Approach to the Treatment of Urinary Incontinence. Urologic Clinics of North America, 18, 393-407.

[2] Hohlbrugger, G. (1999) Urinary Potassium and the Overactive Bladder. BJU International, 83, 22-28. http://dx.doi.org/10.1046/j.1464-410X.83.s2.8.X

[3] Geppetti, P., Tramontana, M., Patacchini, R., Del Bianco, E., Santicioli, P. and Maggi, C.A. (1990) Neurochemical Evidence for the Activation of the "Efferent" Function of Capsaicin-Sensitive Nerves by Lowering of the $\mathrm{pH}$ in the Guinea-Pig Urinary Bladder. Neuroscience Letters, 114, 101-106. http://dx.doi.org/10.1016/0304-3940(90)90435-C

[4] Hohlbrugger, G. (1996) Leaky Urothelium and/or Vesical Ischemia Enable Urinary Potassium to Cause Idiopathic Urgency/Frequency Syndrome and Urge Incontinence. International Urogynecology Journal, 7, 242-255. http://dx.doi.org/10.1007/BF01901246

[5] Lavin, J.M., Hosker, G.L. and Smith, A.R.B. (1997) Dose Urinary pH Influence Micturition Desire? Neurourology and Urodynamics, 16, 396-397.

[6] Rentzhog, L. and Sundström, G. (1990) Micturition Reflex Disturbances-A Neglected Diagnosis. Neurourology and Urodynamics, 9, 355-356.

[7] Hohlbrugger, G., Lentsch, P., Pfaller, K. and Madersbacher, H. (1985) Permeability Characteristics of the Rat Urinary Bladder in Experimental Cystitis and after Overdistension. Urologia Internationalis, 40, 211-216. http://dx.doi.org/10.1159/000281082

[8] Jiang, C.H. and Lindstrom, S. (1996) Intravesical Electrical Stimulation Induces a Prolonged Decrease in Micturition Threshold Volume in the Rat. The Journal of Urology, 155, 1477-1481. http://dx.doi.org/10.1016/S0022-5347(01)66310-9

[9] Keast, J.R., Booth, A.M. and De Groat, W.C. (1989) Distribution of Neurons in the Major Pelvic Ganglion of the Rat which Supply the Bladder, Colon or Penis. Cell and Tissue Research, 256, 105-112. http://dx.doi.org/10.1007/BF00224723

[10] Jiang, C.H. (1998) Modulation of the Micturition Reflex Pathway by Intravesical Electrical Stimulation: An Experimental Study in the Rat. Neurourology and Urodynamics, 17, 543-553. http://dx.doi.org/10.1002/(SICI)1520-6777(1998)17:5<543::AID-NAU11>3.0.CO;2-G

[11] Hauser, P.J., Buethe, D.A., Sofinowski, T.M., Culkin, D.J., Hurst, R.E. and Califano, J. (2009) Restoring Barrier Function to Acid Damaged Bladder by Intravesical Chondroitin Sulfate. The Journal of Urology, 182, 2477-2482. http://dx.doi.org/10.1016/j.juro.2009.07.013

[12] Lee, J.W., Pak, S.C. and Jeon, S. (2012) Modified Yukmijihwangtang Suppresses the Production of Proinflammatory Cytokines in the Intravesical Hydrochloric Acid-Induced Cystitis Rat Model via the NF- $\kappa \mathrm{B}$ Pathway. The American Journal of Chinese Medicine, 40, 321-334. http://dx.doi.org/10.1142/S0192415X12500255

[13] Zeng, J.W., Xie, K.J., Jiang, C.H., Mo, J.F. and Lindstrom, S. (2012) Bladder Mechanoreceptor Changes after Artificial Bladder Outlet Obstruction in the Anesthetized Rat. Neurourology and Urodynamics, 31, 178-184. http://dx.doi.org/10.1002/nau.21219

[14] Zeng, J.W., Pan, C.Z., Jiang, C.H. and Lindstrom, S. (2012) Cause of Residual Urine in Bladder Outlet Obstruction: An Experimental Study in the Rat. The Journal of Urology, 188, 1027-1032. http://dx.doi.org/10.1016/j.juro.2012.04.101

[15] Hohlbrugger, G. and Lentsch, P. (1985) Intravesical Ions, Osmolality and pH Influence the Volume Pressure Response in the Normal Rat Bladder, and This Is More Pronounced after DMSO Exposure. European Urology, 11, 127-130.

[16] Nguan, C., Franciosi, L.G., Macleod, B.A., Jens, M., Fenster, H.N. and Butterfield, N.N. (2005) A Prospective, Double-Blind, Randomized Cross-Over Study Evaluating Changes in Urinary pH for Relieving the Symptoms of Interstitial Cystitis. BJU International, 95, 91-94. http://dx.doi.org/10.1111/j.1464-410X.2004.05257.x 
[17] Sethia, K.K. and Smith, J.C. (1987) The Effect of pH and Lignocaine on Detrusor Instability. British Journal of Urology, 60, 516-518. http://dx.doi.org/10.1111/j.1464-410X.1987.tb05032.X

[18] Hara, S., Tsuji, H., Amakawa, K., Hsieh, S.D., Arase, Y., Nakajima, H. and Ohmoto, Y. (2012) High Serum Uric Acid Level and Low Urine $\mathrm{pH}$ as Predictors of Metabolic Syndrome: A Retrospective Cohort Study in a Japanese Urban Population. Metabolism, 61, 281-288. http://dx.doi.org/10.1016/j.metabol.2011.06.026

[19] Sengupta, J.N. and Gebhart, G.F. (1994) Mechanosensitive Properties of Pelvic Nerve Afferent Fibers Innervating the Urinary Bladder of the Rat. Journal of Neurophysiology, 72, 2420-2430.

[20] Uvelius, B., Andersson, P.O. and Malmgren, A. (1990) Effects of Variations in Extracellular pH on Spontaneous Contractile Activity and Response to Nerve Stimulation in Smooth Muscle from Rat Urinary Bladder. Scandinavian Journal of Urology and Nephrology, 24, 47-51. http://dx.doi.org/10.3109/00365599009180359

[21] Geppetti, P., Del Bianco, E., Patacchini, R., Santicioli, P., Maggi, C.A. and Tramontana, M. (1991) Low pH-Induced Release of Calcitonin Gene-Related Peptide from Capsaicin-Sensitive Sensory Nerves: Mechanism of Action and Biological Response. Neuroscience, 41, 295-301. http://dx.doi.org/10.1016/0306-4522(91)90218-D

[22] Sharma, A.P. and Manchanda, S.K. (1959) Vesico-Renal Reflex. Indian Journal of Medical Research, 47, 318-321. 
Scientific Research Publishing (SCIRP) is one of the largest Open Access journal publishers. It is currently publishing more than 200 open access, online, peer-reviewed journals covering a wide range of academic disciplines. SCIRP serves the worldwide academic communities and contributes to the progress and application of science with its publication.

Other selected journals from SCIRP are listed as below. Submit your manuscript to us via either submit@scirp.org or Online Submission Portal.
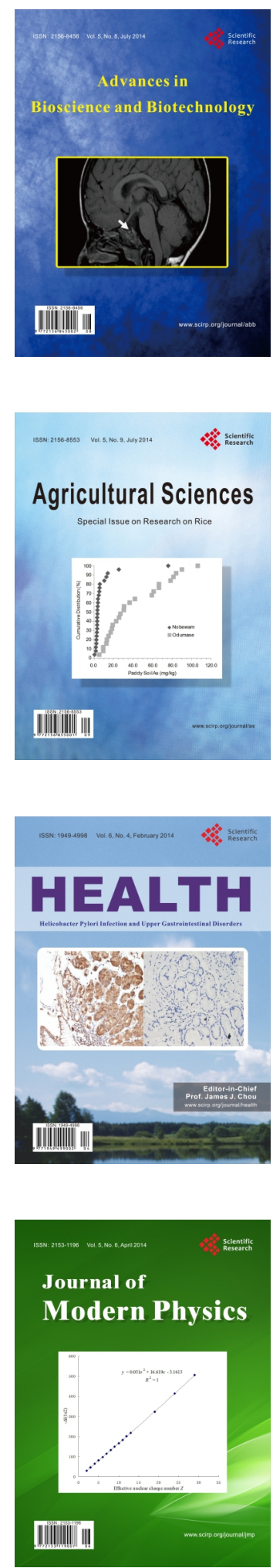
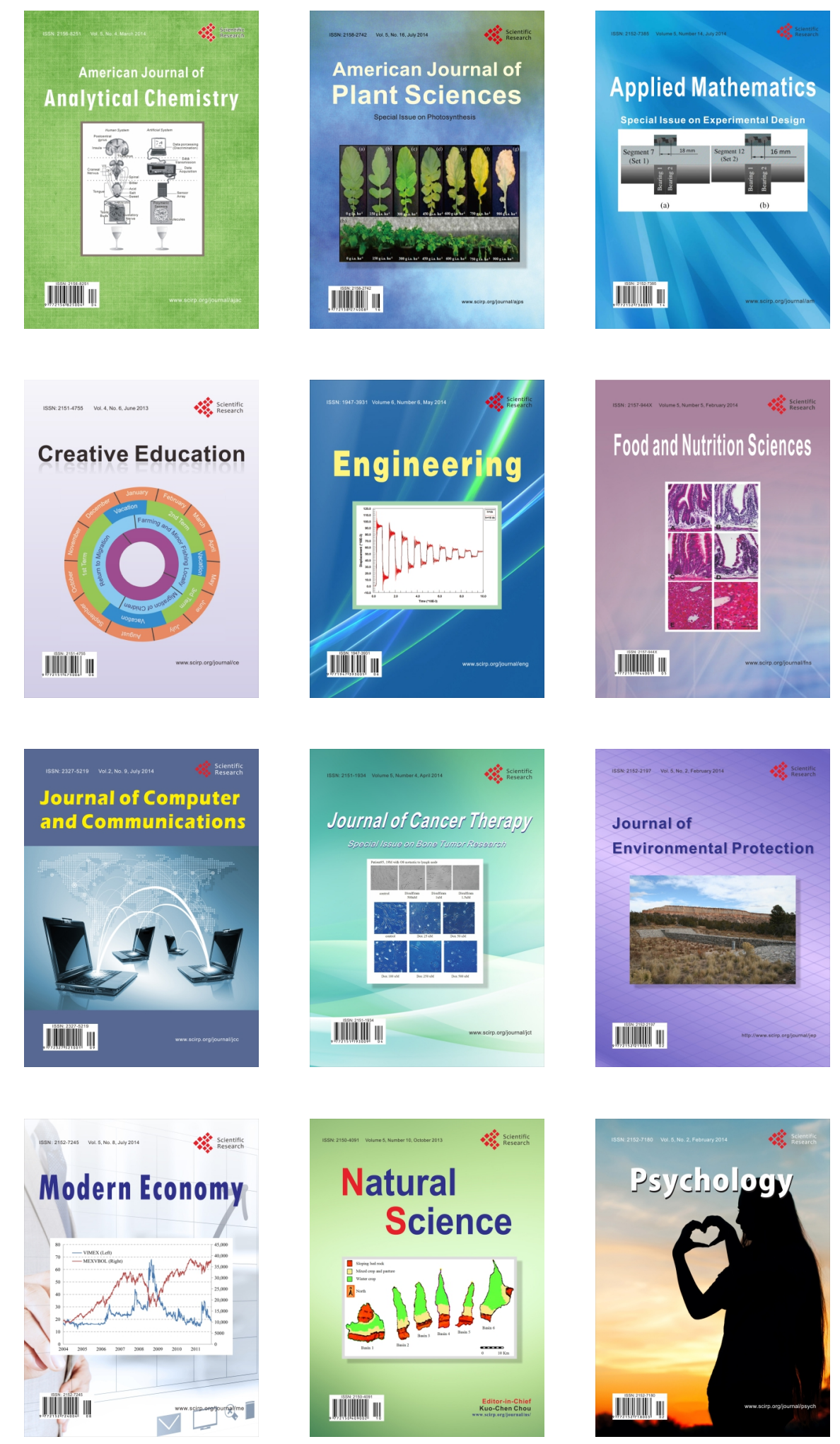